\title{
Review Lakon Sastrajendra Hayuningrat Pangruwating Diyu Wahana Eksplorasi Model Perancangan Lakon Dalam Rangka "Njajab Désa Milang Kori"
}

\section{B. Djoko Suseno}

Jurusan Pedalangan Fakultas Seni Pertunjukan Institut Seni Indonesia Yogyakarta Email: -

\begin{abstract}
Njajah désa milang kori program is an activity of going around from one place to another in Bantul regency. This activity is one of the moral responsibility of the academic civitas of Pedalangan FSP ISI Yogyakarta for the world's recognition of wayang kulit, which in fact began to have signs of fading in Bantul society. The move is intended as a vehicle to increase the appreciation of the community as well as improving the ability of dalang, both for lecturers and students majoring Pedalangan ISI Yogyakarta. The program is a place to experiment and explore new formats of wayang performances according to the demands of the era. One of these steps is reusing Lakon Alap-alapan Sukèsi by Ki Nartosabdo into the Ngayogyakarta tradition in a concise format. The questions are: (1) What elements are considered in the re-work; (2) Whether the results are still following the rules of the puppetry; and (3) whether the results of the work have met the criteria of the demands of the times. Through the study of balungan balungan plays and the concept of rap-rapet obtained the conclusion that: (1) Issues submitted are only the main points only; (2) Broadly speaking the plays still follow the pattern of pathet by reducing the jejer and the scene; (3) It meets the demands of the times, new in the aspect of the duration of time; and (4) have not been able to produce a show that seems relaxed and less able to build a living reality. The results of this study are expected to intensify the re-evaluation so that the purpose of developing the world of puppetry can be achieved.
\end{abstract}

Keywords: njajah désa; re-work; Sukèsi; plays; new format

\begin{abstract}
Abstrak
Program njajah désa milang kori adalah sebuah kegiatan mendalang berkeliling dari satu tempat ke tempat yang lain di Kabupaten Bantul. Kegiatan ini merupakan salah satu bentuk tanggung jawab moral civitas akademika jurusan Pedalangan FSP ISI Yogyakarta atas pengakuan dunia terhadap wayang kulit, yang pada kenyataannya mulai ada tanda-tanda memudar pamornya dalam masyarakat Bantul. Langkah tersebut dimaksudkan sebagai wahana peningkatan apresiasi masyarakat sekaligus peningkatan kemampuan mendalang, baik bagi dosen maupun mahasiswa jurusan Pedalangan ISI Yogyakarta. Program tersebut merupakan ajang bereksperimen dan mengekplorasi format baru pertunjukan wayang sesuai dengan tuntutan jamannya. Salah satu dari langkah tersebut adalah garap-ulang Lakon Alap-alapan Sukèsi oleh Ki Nartosabdo ke dalam tradisi Ngayogyakarta dalam format pakeliran ringkas. Yang
\end{abstract}


menjadi pertanyaan adalah: (1) Unsur apa saja yang diperhatikan dalam garap-ulang tersebut; (2) Apakah hasil garap tersebut masih mengikuti kaidah-kaidah dalam pedalangan; dan (3) Apakah hasil garap tersebut sudah memenuhi kriteria tuntutan jaman. Melalui telaah pola balungan lakon dan konsep sambung-rapet diperoleh kesimpulan bahwa: (1) Permasalahan yang disampaikan hanyalah yang pokok-pokok saja; (2) Secara garis besar lakon masih mengikuti pola pathet dengan mengurangi jejer dan adegan; (3) Hal yang memenuhi tuntutan jaman, baru dalam aspek durasi waktu; dan (4) Belum mampu menghasilkan pertunjukan yang terkesan santai dan kurang mampu membangun realitas yang hidup. Hasil penelitian ini diharapkan semakin menggiatkan telaah ulang sehingga tujuan pengembangan dunia pedalangan dapat tercapai..

Kata kunci: njajah désa; garap-ulang; Sukèsi; lakon; format baru

\section{Pendahuluan}

Sebagaimana realitas yang ada bahwa intensitas pertunjukan wayang kulit purwa, terutama di lingkungan masyarakat kota dan sekitarnya sudah banyak berkurang. Pada umumnya, alasan utama dari persoalan tersebut adalah kendala durasi waktu yang dipandang terlalu lama, yaitu delapan jam atau semalam suntuk. Hal demikian dipandang tidak sesuai dengan situasi dan kondisi masyarakat sekarang yang relatif sudah tidak lagi memiliki waktu luang yang banyak. Mereka dituntut untuk bekerja setiap hari. Oleh karena itu mereka harus menjaga kondisi fisiknya dengan istirahat yang cukup agar keesokan harinya tidak mengantuk ketika bekerja. Hal demikian yang menyebabkan habisnya penonton pertunjukan wayang ketika sudah masuk tengah malam. Oleh karena itu untuk menghadapi fenomena semacam ini diperlukan format pertunjukan yang tidak memerlukan waktu panjang.

Salah satu langkah yang dilakukan oleh civitas akademika Jurusan Pedalangan FSP ISI Yogyakarta adalah menyelenggarakan program njajah désa milang kori. Padmosoekotjo (1958: 66) menjelaskan bahwa njajah désa milang kori mempunyai arti njajah désa tekan ngendi-endi, lan prasasat kabèh panggonan, nganti tekan papan sing tjilik-tjilik lan kiwa, ditekani sarta disetitèkaké kahanané ('keluar masuk di berbagai penjuru desa, untuk melihat dan memperhatikan keadaan semua tempat (dan masyarakat di desa tersebut), bahkan sampai tempat yang sepi-sepi dan terpencil'). Ungkapan tersebut memberikan penjelasan bahwa njajah désa milang kori merupakan kegiatan kemanusiaan yang dilakukan baik perorangan maupun berkelompok dalam rangka mengunjungi, melihat, memperhatikan berbagai desa atau tempat untuk mendapatkan masukan maupun informasi mengenai situasi dan kondisi tempat yang dikunjungi. Lebih jauh Spillane ( 1987: 20) menjelaskan bahwa kegiatan perjalanan keluar masuk desa adalah sebuah kegiatan yang bertujuan untuk mendapatkan kenikmatan, kepuasan mengenai sesuatu sekaligus memberikan hiburan kepada daerah atau tempat yang dikunjungi. Kecuali itu kegiatan perjalanan sementara dari satu tempat ke tempat lain tersebut sebagai usaha untuk mencari keseimbangan atau keserasian hidup dalam dimensi sosial, budaya, alam, dan ilmu yang kemudian disebut dengan istilah pariwisata (Spillane, 1987:21).

Dua penjelasan di atas menjadi inspirasi bagi dosen dan mahasiswa Jurusan Pedalangan FSP ISI Yogyakarta untuk melakukan kegiatan njajah désa milang kori selama 11 bulan. Dosen dan mahasiswa bersinergi untuk menyelenggarakan pementasan wayang kulit purwa, yang untuk sementara ini difokuskan di Kabupaten Bantul sebagai daerah tujuan diselenggarakannya program tersebut. Dosen dan mahasiswa sebagai pendukung utama program ini memiliki pemahaman dan pandangan yang sama untuk mendorong dan mewujudkannya. Program tersebut ternyata mendapat sambutan yang baik dan respon positif dari Yayasan Kertagama Jakarta dan pemerintah desa di wilayah Kabupaten Bantul yang kemudian diwujudkan dalam bentuk kerja sama. Program kerja sama ini mempunyai tujuan pokok pelestarian dan pendekatan kembali seni pewayangan dan pedalangan kepada masyarakat, 
yang kini dirasakan mengalami kemunduran. Tujuan lain program ini ialah untuk pengembangan dan peningkatan ketrampilan mahasiswa, serta melatih mahasiswa pentas di hadapan masyarakat langsung. Oleh karena latar belakang kerja sama adalah untuk pengembangan Jurusan Pedalangan secara umum, maka pelaksanaannya dilakukan secara bergilir antara dosen dan mahasiswa.

Salah satu lakon yang dipentaskan dalam program tersebut adalah lakon Sastrajéndra Yuningrat Pangruwating Diyu. Berkaitan dengan tujuan program ini yaitu sebagai sarana bereksperimen dan bereksplorasi, maka dilakukan alih format lakon Dasamuka Lahir tradisi Surakarta yang dibawakan oleh Ki Nartosabdo almarhum dalam bentuk pita kaset rekaman produksi Fajar Record yang telah di renew oleh PT Bintang Fajar Cassete pada tahun 2009, ke dalam format pakeliran ringkas tradisi Ngayogyakarta dengan lakon Sastrajéndra Yuningrat Pangruwating Diyu. Hasil penelitian ini akan diimplementasikan sebagai dasar perancangan karya seni pedalangan kepada para mahasiswa. Berdasarkan persoalan di atas, yang menjadi pertanyaan adalah: (1) Unsur apa saja yang diperhatikan dalam garap-ulang tersebut; (2) Apakah hasil garap tersebut masing mengikuti kaidah-kaidah dalam pedalangan; dan (3) Apakah hasil garap terebut sudah memenuhi kriteria tuntutan jaman.

Berkenaan dengan persoalan penelitian di atas, Kasidi (2009: 68) dalam Suluk Wayang Kulit Purwa Gaya Yogyakarta menjelaskan bahwa secara epistemologi struktur bangunan lakon wayang yang disajikan secara lengkap terbagi ke dalam 3 (tiga) wilayah pathet yaitu: pathet nem, pathet sanga dan pathet manyura. Masing-masing pathet berisi tentang jabaran-jabaran atau urutan-urutan pasti dan mengikat sesuai dengan tradisi yang berlaku yang disebut pakem, yang terdiri dari: 1) jejer yaitu sebuah pertemuan yang berlangsung di istana dan dihadiri oleh para punggawa kerajaan. Pada saat itu di hadapan para punggawa kerajaan, raja menyampaikan berita utama sebagai pokok bahasan. Kecuali itu juga disampaikan berbagai pendapat maupun solusiyang harus ditempuh untuk mengatasi masalah. Berbagai permasalahan yang disampaikan dalam jejer tersebut merupakan inti dari sebuah lakon; 2) adegan yaitu sebuah peristiwa atau kegiatan yang dalam pertunjukan wayang kulit biasa berlangsung di luar jejer (bandingkan dengan Becker, 1979: 228-230). Lebih jauh Kasidi (2009: 69 ) menjelaskan bahwa adegan ini bisa berupa a) gapuran, b) paséban njawi, c) budhalan maupun adegan lain yang terjadi di luar istana. Dijelaskan bahwa adegan gapuran adalah sebuah adegan yang menceritakan tentang keindahan dan keistimewaan sebuah bangunan berbentuk gapura atau pintu gerbang istana. Paséban njawi yaitu sebuah adegan yang berlangsung di pagelaran, sebuah bangunan besar dan luas tempat para prajurit menantikan berita yang menjadi pokok bahasan sidang di dalam istana. Budhalan, kapalan yaitu suatu adegan yang menggambarkan sekelompok prajurit yang sedang berangkat - budhal- meninggalkan kerajaan dengan naik kuda atau kendaraan lain -kapalan- menuju tujuan sesuai dengan pokok bahasan dalam jejer. Perang, yaitu sebuah adegan yang menggambarkan konflik kepentingan antara satu pihak dengan pihak lain lalu terjadilah perang. Walaupun dalam penyajian pertunjukan wayang tidak selalu ada adegan perang, tergantung cerita yang ditampilkan, namun bangunan piramid ketiga unsur tersebut pasti ada dan selalu menjadi dasar acuan dalam sebuah pertunjukan wayang (gambar 1).

Penentuan dan penyusunan masing-masing unsur dalam pola bangunan lakon wayang harus memperhatikan sambung-rapet, yang meliputi tema, alur, penokohan dan setting. Hal ini penting untuk menjaga mulihé lakon (Wahyudi, 2014: 10-11). Dijelaskan bahwa dalam garap ulang lakon wayang, permasalahan yang ditampilkan dalam setiap adegan harus mengacu dan merujuk pada tema serta menyesuaikan dengan kapasitas tokoh yang membawa permasalahan tersebut. Pergerakan peristiwa dan pengembangan cerita harus membangun alur yang logis.

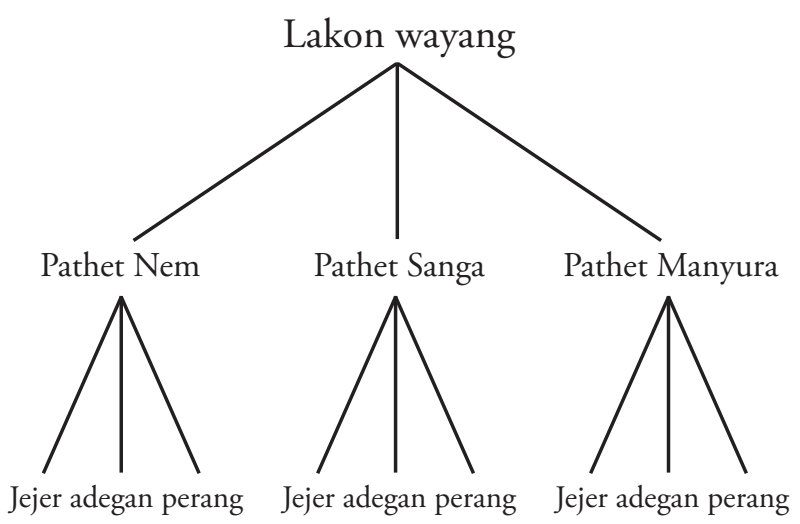

Gambar 1. Bangunan piramid lakon wayang. 


\section{Struktur Bangunan Lakon Alap-alapan Sukèsi Ki Nartosabdo}

Setelah dikaji berdasarkan struktur bangunan lakon seperti dikemukakan di atas, pertunjukan wayang kulit Lakon Alap-alapan Sukèsi yang dibawakan oleh Ki Nartosabdo, urutan pengadegannya adalah sebagai berikut.

Pathet Nem terdiri atas: (1) Jejer negara Lokapala; (2) Adegan kedhatonan; (3) Adegan paséban njawi; (4) Adegan budhalan; (5) Adegan Kerajaan Madyantara; (6) Adegan perang; (7) Adegan kasatriyan Argalobang; (8) Adegan perang. Pathet Sanga terdiri atas: (1) Adegan di Desa Klampisireng; (2) Adegan dalam hutan; (3) Perang. Pathet Manyura terdiri atas: (1) Adegan Kerajaan Ngalengka; (2) Adegan di Kahyangan Suralaya; (3) Adegan patunggon/kaputrèn; (4) Adegan kasatriyan Argalobang; (5) Perang Jambumangli vs BegawanWisrawa; (6) Adegan patunggonl kaputrèn; (7) Adegan Kerajaan Lokapala; (8) Adegan Ngalengka, Perang; (9) Adegan patunggon/ kaputrèn; (10) tancep kayon.

Mencermati paparan adegan menurut pembagian wilayah pathet dalam Lakon Alap-alapan Sukèsi di atas dapat dikatakan bahwa pada tiap-tiap pathet terjadi pengulangan maupun penambahan adegan. Bangunan lakon yang disampaikan oleh Ki Nartosabdo dalam pertunjukan tersebut di sampaikan dalam gaya Surakarta. Seperti diketahui bahwa dalam pertunjukan wayang kulit gaya Surakarta semalam suntuk hanya terdapat satu jejer yaitu jejer pertama (Nojowirongko 1960: 69), sedangkan lainnya berupa adegan. Hal demikian dimungkinkan bisa saja terjadi karena semua adegan yang ditampilkan itu disesuaikan dengan kebutuhan lakon yang erat kaitannya dengan adegan atau bahkan jejer (Kasidi, 2009: 69-70). Semua itu bisa dibuktikan dan terjadi pada pathet manyura yang hampir seluruhnya berisi adegan. Namun demikian jika dicermati lebih dalam sebenarnya terdapat bangunan-bangunan lebih kecil yang mampu menjelaskan keberadaan adegan di sana antara lain: 1) deskripsi yaitu yang berupa janturan, kandha, dan carita; 2) dialog antar tokoh dalam wayang lazim disebut pocapan atau ginem, serta 3) tindakan atau gerak wayang yang disebut oleh Kasidi (2009: 70), Mujanattistomo (1977: 11), serta Nojowirongko (1960: 48) dengan istilah sabetan.
Setelah mencermati naskah Lakon Alap-alapan Sukèsi dilakukan perubahan untuk menghasilkan model perancangan sederhana yang diharapkan menjadi lebih menarik, sebagaimana dijelaskan Bandem (2000: 5-8) bahwa agar pertunjukan yang disajikan tampil lebih menarik dan memikat, maka perlu adanya perubahan-perubahan berdasarkan tuntutan jaman. Sejalan dengan pendapat tersebut Kasidi (2000: 85) juga menjelaskan lebih ditail bahwa perubahan seni pertunjukan bisa terjadi berkat majunya pola pikir manusia seiring dengan modernisasi di segala bidang, perubahan jaman, globalisasi, dan teknologi informasi. Namun demikian perubahan itu bukan berarti merombak secara total pola pertunjukan yang sudah ada, melainkan lebih mengarah pada langkah-langkah inovatif menuju kekinian dengan pijakan tradisi (Bandem, 2000: 5). Lakon Alap-alapan Sukèsi di atas merupakan lakon wayang format semalam suntuk. Oleh karena itu dapat dipahami bahwa kehadiran masing-masing adegan tersebut dalam rangka memenuhi kaidah konvensional lakon wayang. Namun demikian dalam memenuhi kebutuhan masyarakat jaman sekarang khususnya dari aspek waktu maka Lakon Alap-alapan Sukèsi tersebut di atas telah dilakukan garap ulang dalam bentuk pakeliran ringkas tradisi Ngayogyakarta menjadi Lakon Sastrajéndra Hayuningrat Pangruwating Diyu, dengan durasi waktu kurang lebih tiga jam. Beberapa adegan telah dihilangkan, dan beberapa adegan yang lain dipersingkat. Garis besar pola bangunan Lakon Sastrajéndra Hayuningrat Pangruwating Diyu adalah sebagai berikut.

\section{Format Pakeliran Ringkas Lakon Sastra- jéndra Hayuningrat Pangruwating Diyu Gaya Yogyakarta}

\section{Jejer I Ngalengkadiraja}

Iringan :Ayak-Ayak, Gd. Karawitan Sléndro Nem

Tokoh : Prabu Sumaliraja yang juga disebut Prabu Mangliawan, Jambu Mangli, dan perwakilan raja sèwu

Isi cerita :Prabu Sumaliraja sedang membicarakan masalah Dewi Sukèsi yang sedang menghadapi raja penglamar. Jambumangli mengajukan sayembara perang agar ksatria yang men- 
jadi suami Dewi Sukèsi adalah orang yang sangat sakti. Prabu Sumaliraja menerima dengan berat hati. Prabu Kurambanadéwa, raja Simbar Manyura; Prabu Hadisuradenta, raja Gelar Jagad; Prabu Bantaranjagad, raja Trangbulan Jagad; dan Prabu Marondapati raja Mbeloran, naik sitinggil untuk meminta jawaban atas lamaran mereka. Jambumangli menjawab, bahwa untuk mendapatkan Dewi Sukèsi harus mengikuti sayembara perang melawan dirinya. Raja pelamar menerima tantangan tersebut, bodholan.

\section{Adegan di Gelanggang Sayembara Perang}

Iringan : Playon Lasem Sléndro Pathet Nem

Tokoh : Jambumangli dan Raja Sèwu

Isi cerita : Jambumangli perang tanding satu per satu melawan Raja Sèwu. Raja Sewu dapat dikalahkan Jambumangli.

Adegan Jambumangli dengan Para Prajurit Raksasa Ngalengka

Iringan :Playon Lasem

Tokoh : Jambumangli dan beberapa prajurit raksasa

Isi cerita :Jambumangli menanyakan keadaan raja sewu. Para prajurit menyatakan bahwa raja sèwu telah lari meninggalkan negara Ngalengka. Prajurit disuruh berhati-hati dan waspada. Semua setuju, Jambumangli kembali ke istana.

\section{Jejer II Negari Lokapala}

Tokoh : Prabu Danapati, Begawan Wisrawa, Patih Banindra

Iringan : Bondhèt Pélog Nem

Isi cerita :Prabu Danapati memohon kepada Begawan Wisrawa, ayahnya, untuk melamarkan Dewi Sukèsi. Begawan Wisrawa sanggup, kemudian minta pamit untuk melaksanakan tugas. Bodholan.

Adegan Perjalanan Wisrawa

Iringan : Lasem Pélog Pathet Nem

Tokoh : Begawan Wisrawa

Isi cerita : perjalanan Wisrawa.

\section{Adegan Gara-Gara}

Iringan :Ayak-ayak Sléndro Sanga dilanjutkan Playon Sanga

Tokoh : :Semar, Gareng, Petruk, Bagong

Isi cerita : Panakawan bersendau-gurau.

Keterangan: Dalam adegan gara-gara yang keluar pertama kali adalah tokoh Petruk kemudian berturut-turut Garèng dan Bagong. Pokok pembicaraan berdasarkan improvisasi dalang yang bersangkutan. Biasanya yang menjadi fokus pembicaraan adalah situasi yang tengah terjadi pada lingkungan kehidupan sehari-hari, dan diselangseling dengan bernyanyi dan menari, sampai mereka lupa bahwa harus mengabdi kepada orang tua. Lalu tiba-tiba saja Lurah Semar muncul mengingatkan mereka, akhirnya bersama-sama menemui Begawan Wisrawa yang bertamu di kediaman Lurah Semar di Klampis Ireng.

Contoh klise dalam adegan gara-gara:

Setelah ketiga anak Semar bersendau-gurau sejenak, maka terjadilah perselisihan hingga mereka bertengkar. Dalam adegan ini iringan biasanya adalah Sampak Sléndro Pathet Sanga. Semar keluar gamelan suwuk dilanjutkan sulukan yang khusus untuk Semar sebagai berikut.

Suluk Sléndro Sanga khusus Semar:

Semar ika dèn prayitna,

semu riris ika balik,

titi yoni ganda yoni,

tri sonya purnama sasi, aé-ana,

gilar-gilar semèdi tengahing latar,

milangana lintang Bimasekti...ha

Disambung dengan Suluk Jingking Wetah

Sléndro Pathet Sanga:

Titi tundha gagating ngarang,

tri sunthi winayang jati,

kapat mangka kalima candhala,

mangka kalima candhala, aé-ana,

leng-lenging jagad sanyata,

pat-upaté ula lanang, aé-ana;

pat-upaté ula lanang.

pangiridé kebo dhunggul, sasisih sapi gumarang; Jineman

Tri watgatra tundha,

yèn pitika kulawu bendha, 
pat -upaté ula lanang, nang dhung dhang tak dhung dhang tung gong.

Kandha khusus Gara-gara:

Clorooot jegur, Sasireping gara-gara sidhem premanem datan ana sabawaning walang salisik, amung swara jumegur ana ing samodralaya minangka angurmati wijilira Ki Lurah Semar Badranaya, Bogajati, Dhudha Manganang Unung, Sang Hyang Ismaya, ya sang Juru Dyah Santa Prasanta saben mijil kinurmatan alun banthèng amarga aja dupèh mung gedibal saupamané nanging sejati déwa mangéjawantah, tumurun ing madyapada kinarya pamomonging satriya tanah Jawa wiwit saka Bambang Bremani trah tumerah ratu tanah Jawa. Kinarya seksi kagungan putra tiga Garèng, Pétruk sumawana Bagong. Nalika semanten priksa pating grubyak pating grubyuk para putra sami gegojègan, sinareng Ki Lurah Semar mijil sami dipuntilar ingkang putra tetiga. Candrané Ki Lurah Semar dadi Tembang Pocung. Tembang Pocung Sléndro Manyura khusus Semar:

Luwih iwuh,

Lurah Semar yèn ginunggung,

yèn jaluwa samar,

jaja mungal lir pawèstri,

Jineman

yèn èstriya-yèn èstriya,

Lurah Semar kekuncungan

Ginem khas Semar

Semar :Ih ah ih èh èh èh blegegeg ugeg-ugeg sadulita hemèl-hemèl, sasuwéné padha pating grubyuk anak-anakku iki mau, bareng wong tuwa metu saka jero omah, banjur cep klakep ora ana benèké kaya orong-orong kepidak, gèk bocah-bocah iki mau padha ana ngendi. Tholé anak-anakku kowé mrénéa bapak ora duka. Haaa kok ora ana wangsulan sithik-sithika. Nala Garoèng, Pétruk, lan Bagong padha nyeraka mréné Tholéé... Tak undanga nganti ngentèkké swara ora bakal krungu mapan pancèn wis klebu dadi unèn-unèn nèk olèbku ngundang ora nganggo tembang, tangèh lamun padha nyerak. Ha duwé anak telu wé édan patbelas. Njajal tak tembangné Barang Miring Sléndro Manyura bèn nyamleng.
Suluk Barang Miring Sléndro Manyura: Adhuh yana, adhuh yana tak nembanga, sekar sétan, gendruwo mimba thèthèkan; Sekar sétan gendruwo mimba thèthèkan, aja mamang, mburimu ana janggitan. Adhuh yana tak nembanga iku maning, lir kawista, leting tembang saupama, aja nganggep yèn sira durung waspada.

Tembang Mijil Sléndro Manyura khusus Gareng: Lara-lara larané kang ati, nora kaya ingong, barang karya wus nglakoni kabèh, loro-loro kang durung nglakoni, mukti karo sugih, begjané wak ingsun.

Irim-Irim Laras Wangi khusus Petruk:

Lunging gadhung rumambat wit krambil gadhing, ana randha menyang sendhang, medhak-medhok nyangking méndhong, manuk podhang méncok néng papah gedhang, anucuki wohing kemundhung, kyai dhudha ngumbah gadhung keplèsèt kecemplung kedhung, yung yung biyung nyoh anakmu, gonal-ganèl.

Dilanjutkan buka celuk disambung Gendhing Ladrang Sarayuda Sléndro:

Pak aku gemang dipondhong sing klambi abang Tembang Gambuh Sléndro khusus Bagong:

Sega penak wak duduh,

sambel gorèng tur peténé Manyura wutuh, gudheg manggar iwak pitik santen kanil, iwak empal abon remus, berongkosé iwak congor, réré jangan paré, térong kopèk ngajak bléndrong.

Disambung gendhing Bléndrong Sléndro Manyura.

\section{Jejer III Karang Kebolotan}

Iringan : Pangkur Sléndro Sanga

Tokoh : Wisrawa, Semar, Garèng, Petruk, Bagong

Isi cerita : Wisrawa meminta kepada Semar dan anak-anaknya untuk menyertainya ke Ngalengka guna melamar Dewi Sukèsi. Semua setuju, berangkat.

\section{Adegan Perang Bégal}

Iringan : Playon Sanga 
Tokoh : Wisrawa, panakawan, buta begal Isi cerita : Wisrawa dan panakawan, di tengah perjalanan bertemu dengan prajurit raksasa dari negara Trancangkencana yang dipimpin Dityakala Klanthang Mimis. Terjadi perselisihan, kemudian perang. Semua raksasa berhasil dikalahkan, mereka melanjutkan perjalanan.

\section{Jejer IV Negara Ngalengkadiraja}

Iringan :Gendhing Ladrang Sekar Tanjung Sléndro Sanga.

Tokoh : Prabu Sumaliraja, Radèn Prahastha, Begawan Wisrawa

Isi cerita : Prabu Sumaliraja dan Radèn Prahastha, di persidangan sedang membicarakan keadaan Jambumangli. Tidak berselang lama, datang Begawan Wisrawa. Begawan Wisrawa ingin melamar Dewi Sukèsi untuk putranya, Prabu Danaraja. Prabu Sumaliraja mengatakan bahwa Sukèsi memiliki permintaan yaitu calon suaminya harus bisa mengajarkan ilmu Sastrajéndra Hayuningrat Pangruwating diyu serta harus mengalahkan Jambumangli. Prabu Sumaliraja juga memohon agar dirinya disempurnakan wujudnya sebagai manusia, bukan raksasa lagi. Begawan Wisrawa menyanggupi, dan mengajak Prabu Sumaliraja menuju sanggar pamelengan. Berangkat.

\section{Adegan Patunggon}

Iringan : Playon Sléndro Manyura

Tokoh :Dewi Sukèsi, Begawan Wisrawa

Isi cerita :Begawan Wisrawa menemui Dewi Sukèsi. Sang Begawan mengatakan bahwa kedatangannya untuk melamar Dewi Sukèsi agar bersedia menjadi permaisuri putranya, Prabu Danaraja. Dewi Sukèsi bersedia asalkan calon suami bisa mengajarkan Sastrajéndra Hyuningrat Pangruwating Diyu. Begawan Wisrawa menyanggupi dan meminta Dewi Sukèsi untuk segera mempersiapkan diri guna menerima ajaran Sastrajéndra Ha- yuningrat Pangruwating Diyu. Proses pengajaran ilmu tersebut dalam bentuk tembang dhandhanggula.

Tembang Dhandhanggula Sastrajéndra Pathet Pelog Barang:

Wedhar ingkang Sastrajéndra yekti,

hayuningrat pangruwating yaksa,

sarana kang pangruwaté,

sanggya kang sipat diyu,

praptèng watak pindha raseksi,

hambek angkara murka,

candhala ing kalbu,

hambek siya sirna rasa,

kamanungsan durgama ingkang sinandhing,

sumongah sesongaran.

Keterangan: Masuk ke Gendhing Ladrang ÉlingÉling Pélog Barang gendhing dados, kasirep, dalang membacakan wejangan.

Wejangan:

Wedhar ingkang Sastrajéndra yekti, hayuningrat pangruwating yaksa, sarana kang pangruwaté, sanggya kang sipat diyu, praptèng watak pindha raseksi, hambek angkara murka, candhala ing kalbu, hambek siya sirna rasa, kamanungsan durgama ingkang sinandhing, sumongah sesongaran.

Trus angangkah-angakahi bumi, murih punjul mandhiri priyangga, mrih katekan sasedyané, nanging ngiwaken sujud, manembah Hyang kang murbèng gaib, iblis laknat maksiyat iku déwanipun, tan éling lamun triloka, dumadiné awit parmaning Hyang Widi, cinipta hing kawasa.

Tebih wulang tan wruh ing palupi, hadigang hadigung hadiguna, tan ngawruhi sejatiné, sanggya titah satuhu, tinitabken déning déwadi, sapisan wruh ing tata, titi kalihipun, titis nenggih kaping tiga, kapat tatag lima tutuk mangka kunci, gayuhaning agesang.

Yata wau Sang Wisrawa Resi, amedharken kanang Sastrajéndra, amirid wuruk warahé, sastra tegesé iku, kang kadulu awujud tulis, yekti dadi panuntuning kawruh, lan ngèlmu sanguning gesang, ala becik agal lembat dèn kawruhi, bonggan yèn wuta sastra.

Sastra cetha iku murakabi, datan kéwran nempuh jejibahan, nadyan abot dadi ènthèng, mlampah ing papan lunyu, antuk teken tekun 
nulungi, lamun petenging marga antuk obor sèwu, mungsuh asih dadi sanak, sanak kadang saya supeketing kapti, wangsané hingayoman.

Harjéndrayuyuning basuki, kangmangkono mungguh werdinira, ywa kènger ing panembahé, patrapna sembah catur, kang kapisan yayah lan wibi, dadi marganing tumitah, kalih nembah guru, nyata kang paring piwulang, sembah katri saisiningrat andayani, surya candra kartika. Katri iku winastan trimurti, sesoroté mujudké hyang sukma, gya dumilah pepadhangé, raga dumadinipun, bumi geni banyu lan angin, lagi gatra manungsa, cinipta Hyang Agung, yèn wis agung ngélingana, déné titah tumitah derma nglakoni, wit purbaning kawasa.

Ningrat iku papané jro hurip, kudu bisa wruh ing tata cara, tandang tanduk sasolahé, aja handhedher bendu, lumakuwa dalan kang gasik, durgama singkirana, tingkah sarta laku, dadya tepa tuladha, ing sadhengah wekasan manggih basuki, yaiku sucining gesang.

Sembah catur konjuk mring Hyang Widi, kang sayekti nggelar jagad raya, sangkeb saisènisèné, déné pangruwat diyu, hangilangken candhala julig, amunah sastru murka, kang agung gumulung, hanggeleng ing angganira, sirna larut kérut kendhih tyas basuki, sesuka sukèng driya.

Pra wanodya setya guru laki, ingkang priya tresna marang garwa, ing saloka mujudaké, wewangsoné pra luhur, panunggaling kawula gusti, lahir tumandang kaya jroning batinipun, hangagungken Hyang Suksma, yèn mangkono turun-tumuruning bénjing, dadya manungsa tama.

Keterangan:Pada saat janturan, Bathara Guru dan Dewi Uma digerakkan di atas Begawan Wisrawa dan Dewi Sukèsi, seolah sedang mengawasi sambil membacakan kandha. Selesai wejangan, iringan masih rep-repan Ladrang Éling-éling, dilanjutkan kandha.

Kandha:

Tatas titis tutug tlédhak-tlédhok kaya madu pinasthika wijiling pangendika dyan Wisrawa, samendhang tan ana kang kacicir samukawis wus tinampi déning sang dyah ayu Dèwi Sukèsi. Kocap kacarita sinarengan lelampahan ing madyapada geder gara-gara anggung anggegirisi tumempuh Kahyangan Jonggring Salaka, kaya bojat-bojata kori Séla Matangkep, pindha jomplang-jomplanga umpak BaléMarcukundha, kinocak-kocak Kawah Candramuka, lebu letug metu sembur upas hagni saklapa-klapa gedhéné. Kejot Sang Hyang Hudipati awit dhatenging, cipta wirengganira.

Guru : : : : $\quad$ :engko ta Yayi Dèwi Uma

Uma :Nuwun wonten dhawuh Pukulan Sang Hyang Jagad Nata

Guru :Sungkawaning gara-gara kang nempuh Kahyangan Suralaya kanyata merga saka polah tingkahing jalma aran Begawan Wisrawa kang tumindak sesongaran kaya lanang-lananga priyangga, wani ambabar ngèlmu kekeraning déwa Sastrajéndra Hayuningrat Pangruwating Diyu. Mokal lamun dhèwèké ora mangerti lamun iku dadi laranganing para déwa, jalaran sapa kang krungu wedharaning ngèlmu iku, yèn kutukutu walang ataga bakal dadi sato, sato bakal dadi buta, buta bakal dadi manungsa, yen manungsa bakal dadi déwa. Yèn nganti diuja tumindaké kang mangkono bakal kaya ngapa rusaking jagad raya, kabèb ora mangerti dunungé sapa kang nyembah lan sapa kang kasembah. Ulun bakal paring paukuman marang manungsa kang budiné candhala iki, kita manjinga ana anggané Dèwi Sukèsi déné ulun bakal sajiwa ana anggané Wisrawa

Uma :Inggih ndhèrèk dhateng sendika Pukulun mangga kula dhèrèkaken

Adegan Bathara Guru dan Bathari Uma Manjing ke Begawan Wisrawa dan Dewi Sukèsi.

Iringan :Éling-éling berubah menjadi Playon Pélog Barang

Tokoh : Begawan Wisrawa dan Dewi Sukèsi Isi cerita : Setelah Bathara Guru dan Bathari Uma manjing ke tubuh Bagawan Wisrawa dan Dewi Sukèsi, keduanya menjadi berubah sikap. Dewi Sukèsi jatuh cinta kepada Wisrawa, dan Wisrawa menanggapi. Keduanya memadu cinta. 


\section{Jejer V Adegan Kasatriyan Argalobang}

Iringan : Playon Sléndro Manyura

Tokoh : Jambumangli dan Prajineman

Isi cerita :Jambumangli mendengar berita bahwa Dewi Sukèsi telah menikah dengan Wisrawa. Jambumangli marah dan melabrak Wisrawa.

\section{Adegan Alun-Alun Ngalengka}

Iringan : Playon Sléndro Manyura

Tokoh : Jambumangli, Sumali, Wisrawa

Isi cerita :Jambumangli menemui Prabu Sumaliraja dan Begawan Wisrawa. Jambumangli mencela segala perbuatan Begawan Wisrawa. Ia menantang Begawan Wisrawa untuk perang tanding. Begawan Wisrawa melayani. Terjadi perang tanding. Jambumangli dibunuh Begawan Wisrawa.

\section{Jejer VI Adegan Lokapala}

Iringan : Playon Sléndro Manyura

Tokoh :Prabu Danapati, Banindra, dan Gohmuka

Isi cerita :Prabu Danapati menanyakan kepada Patih Banindra mengenai perjalanan Begawan Wisrawa. Banindra mengatakan bahwa Begawan Wisrawa berhasil masuk ke negara Ngalengka. Tiba-tiba Gohmuka datang dan mengatakan bahwa Dewi Sukèsi telah diperistri Begawan Wisrawa. Prabu Danapati sangat marah dan menyuruh mempersiapkan seluruh pasukan guna menggempur negara Ngalengkadiraja. Berangkat.

\section{Jejer VII Adegan Prabu Danapati berhadapan dengan Begawan Wisrawa \\ Iringan :Playon Galong \\ Tokoh : Begawan Wisrawa, Prabu Danapati, prajurit}

Isi cerita :Prabu Danapati marah karena Begawan Wisrawa telah mengkhianati tugasnya sebagai ayah. Semula Dewi Sukèsi dilamar untuk dirinya, ternyata malah diperistri sendiri. Prabu Danapati bersumpah bahwa bila kelak Begawan Wisrawa dengan Dewi Sukèsi punya anak laki-laki, maka anak tersebut akan menjadi musuh Danapati. Danapati meninggalkan ayahnya, pulang ke Lokapala.

\section{Adegan Perang Brubuh}

Iringan :Sampak

Tokoh : Wisrawa dan prajurit Lokapala

Isi cerita : Prajurit Lokapala tidak terima atas perbuatan Wisrawa. Mereka mengamuk, namun berhasil disapu oleh angin ciptaan Wisrawa. Prabu Sumaliraja mengajak Begawan Wisrawa pulang ke istana Ngalengkadiraja.

\section{Tanceb Kayon}

Berdasarkan teks lakon, baik Alap-alapan Sukèsi maupun Sastrajendra Hayuningrat Pangruwating Diyu di atas tampak bahwa meskipun pola bangunan lakonnya berbentuk piramida tetapi tidak berlaku pola tiga-tiga. Apabila dicermati lebih jauh lagi, sebenarnya pola tiga-tiga ini tidak mungkin terwujud karena dalam tradisi Ngayogyakarta, dalam lakon konvensional hanya terdiri dari tujuh jejer, yakni tiga jejer untuk pathet Nem, dua jejer untuk pathet Sanga, dan dua jejer untuk pathet Manyura. Apabila dibuat pola tigatiga maka harus dibuat sembilan jejer. Berdasarkan pencermatan atas teks lakon Alap-alapan Sukèsi Ki Nartosabdo, apabila pembagian adegannya disesuaikan dengan tradisi Ngayogyakarta, maka dapat dijabarkan sebagai berikut.

Pathet Nem:

1. Jejer I negara Lokapala terdiri dari adegan (1) paséwakan agung negara Lokapala, (2) Adegan kedhatonan, (3) Adegan paséban njawi, (4) Adegan budhalan

2. Jejer II Kerajaan Madyantara terdiri dari adegan

(1) paséwakan agung negara Madyantara, dan

(2) Adegan perang,

3. Jejer III Kasatriyan Argalobang yang terdiri dari (1) adegan di pendapa kasatriyan, dan (2) Adegan perang.

Pathet Sanga:

1. Jejer IV di Desa Klampis Ireng terdiri dari (1) adegan pendapa Klampis Ireng (2) Adegan perang dalam hutan.

2. Jejer VAdegan Kerajaan Ngalengka terdiri dari (1) sitinggil negara Ngalengka.

\section{Pathet Manyura:}

(2) Adegan singgetan di Kahyangan Suralaya, 
(3) Adegan patunggon/kaputren, (4) pendapa kasatriyan Argalobang, (5) Perang Jambumangli vs Begawan Wisrawa, dan (6) Adegan patunggon/kaputren,

1. Jejer VI Kerajaan Lokapala terdiri dari (1) adegan sitinggil negara Lokapala, (2) budhalan pasukan.

2. Jejer VII negara Ngalengka terdiri dari (1) adegan sitinggil negara Ngalengka, (2) adegan perang, (3) Adegan patunggon/kaputren, dan (4) tanceb kayon.

Dengan demikian pembagian adegan tersebut dapat digambarkan dalam gambar 2 dan gambar 3 . Dua pola tersebut menunjukkan adanya perubahan pola bangunan lakon. Lakon Alap-alapan Sukèsi menggunakan pola konvensional yang berlaku dalam tradisi pedalangan Ngayogyakarta dengan pembagian jejer $3: 2: 2$; sedangkan untuk lakon Sastrajéndra Hayuningrat Pangruwating Diyu dilakukan pembalikan, yaitu tiga jejer justru ditaruh dalam pathet Manyura. Artinya garap-ulang lakon tersebut tidak mengikuti pola konvensional. Untuk pembagian adegan pada masing-masing jejer pun justru sebagian besar tidak dibagi menjadi tiga adegan, bahkan ada yang hanya satu adegan. Apabila mencermati pembagian adegan pada masing-masing pathet menunjukkan bahwa kedua garap lakon tersebut adalah lakon yang dawa mburi, yaitu jumlah adegan dalam pathet manyura jauh lebih banyak dibanding jumlah adegan dalam pathet Nem.

Dua teks lakon di atas menunjukkan bahwa telah dilakukan perubahan atas negara yang didudukkan sebagai jejer I, dan hal itu berakibat merubah pula permasalahan yang ditampilkan. Apabila dicermati secara keseluruhan tampak bahwa dalam garap ulang tersebut telah terjadi pula perubahan tema. Lakon Alap-alapan Sukèsi sajian Ki Nartosabdo, secara keseluruhan bertemakan

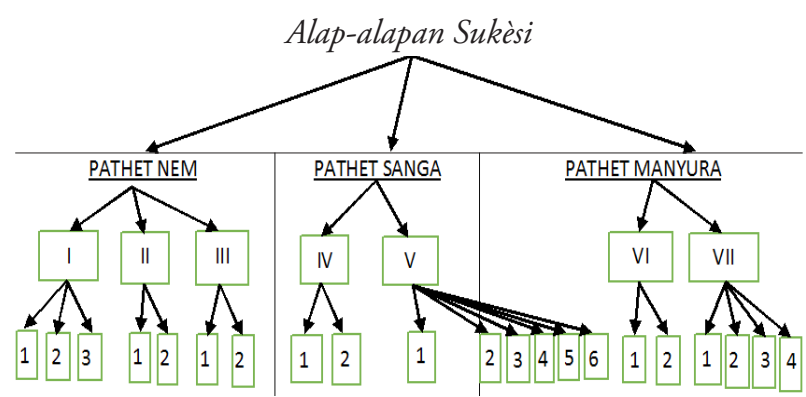

Gambar 2. Pola bangunan lakon Alap-alapan Sukèsi Ki Nartosabdo. "pencarian" (mencari istri). Sejak jejer I, sampai adegan seterusnya, permasalahan yang ditampilkan adalah memperebutkan Dewi Sukèsi untuk dijadikan isteri, baik itu oleh Danaraja, raja-raja pelamar, Jambumangli dan bahkan oleh Wisrawa sendiri. Artinya bahwa permasalahan yang ditampilkan dari jejer I sampai selanjutnya setia kepada tema. Hal demikianlah yang dikatakan bahwa bangunan lakon tersebut mampu membentuk satu kesatuan cerita yang utuh. Berbeda halnya dengan tema yang digunakan untuk membangun Lakon Sastrajéndra Hayuningrat Pangruwating Diyu. Lakon ini lebih berfokus pada peristiwa yang terjadi di negara Ngalengka, yang diawali dengan jejer I negara Ngalengkadiraja. Pembicaraan utama dalam jejer tersebut adalah strategi yang harus diterapkan dalam menghadapi ancaman negara lain terhadap negara Ngalengka maupun Dewi Sukèsi. Berpijak dari persoalan demikian, idealnya bahwa semua peristiwa yang terjadi selanjutnya adalah upaya penyelesaian dari permasalahan jejer $I$, yaitu menyelamatkan negara dari ancaman raja pelamar Dewi Sukèsi, dan sekaligus perlindungan terhadap Dewi Sukèsi sendiri. Namun demikian kehadiran tokoh Wisrawa yang tanpa perlawanan merupakan pengingkaran terhadap pembicaraan Sumaliraja dengan Jambumangli di jejer I. Artinya bahwa sudah mengabaikan pertahanan negara dan Dewi Sukèsi. Dengan demikian dapat dikatakan bahwa kehadiran Wisrawa di sini berada di luar tema lakon. Terlebih lagi apabila mencermati adegan Kasatriyan Argalobang bahwa Jambumangli tidak mengetahui kehadiran Wisrawa. Artinya bahwa Prabu Sumaliraja mengkhianati Jambumangli. Mungkin apabila yang menyaksikan pertunjukan lakon tersebut adalah orang yang sedikit-banyak sudah paham wayang tidak masalah karena mereka mengetahui "kualitas" hubungan Sumali dengan Jambumangli; namun bagi orang yang "buta" la-

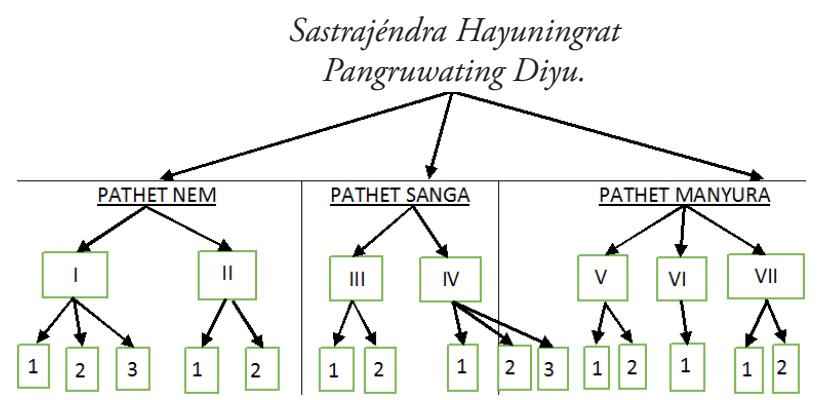

Gambar 3. Pola bangunan lakon Sastrajéndra Hayuningrat Pangruwating Diyu. 
kon, peristiwa tersebut akan membingungkan dan tidak akan mampu memahami peristiwa yang terjadi. Hal tersebut tentu akan berbeda apabila konflik Sumaliraja dengan Jambumangli itu ditunjukkan, baik melalui dialog maupun peristiwa, maka kehadiran Wisrawa justru akan dipahami penonton sebagai penyelamat Ngalengkadiraja dan Sukèsi. Oleh karena petunjuk tersebut tidak ditampilkan maka akibatnya dalam Lakon Sastrajéndra Hayuningrat Pangruwating Diyu ini memiliki dua tema yang saling bertentangan, yaitu perkawinan Sukèsi dan mempertahankan negara Ngalengka dari raja penglamar. Dikatakan bertentangan karena apabila yang digunakan sebagai tema adalah perkawinan Wisrawa dan Dewi Sukèsi, maka permasalahan jejer I berada di luar tema; dan sebaliknya apabila menggunakan tema mempertahankan Ngalengkadiraja dan Dewi Sukèsi dari ancaman raja pelamar, maka kehadiran Wisrawa tanpa bertemu Jambumangli merupakan pengkhianatan Prabu Sumaliraja atas tema. Dengan demikian dapat dikatakan bahwa Lakon Sastrajéndra Hayuningrat Pangruwating Diyu ini memiliki tema ganda sehingga kesatuan yang utuh atas tema dan topik menjadi tidak terbangun dengan baik.

Persoalan yang kedua adalah alur. Alur adalah aksi yang hidup, yang membuat arah pergerakan peristiwa dan pengembangan jalan cerita menjadi logis. Oleh karena pergerakan peristiwa tidak dapat lepas dari kapasitas tokoh dalam adegan, maka dalam hal alur, pembahasannya menjadi satu dengan pembahasan tokoh. Pergerakan peristiwa lakon diawali oleh Prabu Sumaliraja yang mengkhawatirkan keadaan negara Ngalengkadiraja dari amukan raja pelamar Dewi Sukèsi karena Dewi Sukèsi minta babana yang dirasa mustahil untuk dipenuhi. Oleh karena itulah Prabu Sumaliraja mengundang Jambumangli untuk mengatasi persoalan tersebut. Jambumangli ternyata semakin menambah persoalan karena ia pun mengadakan sayembara perang, yaitu siapa pun yang ingin mempersunting Dewi Sukèsi harus mampu mengalahkan dirinya. Pergerakan peristiwa selanjutnya adalah kedatangan raja pelamar yang ditandai dengan kandha. Artinya bahwa peristiwa di sini digerakkan oleh narasi. Oleh karena perwakilan raja pelamar memaksakan kehendaknya maka oleh Jambumangli diajak mengikuti sayembara perang. Mereka setuju, kemudian peristiwa bergerak pada adegan perang yang terjadi di blabar kawat. Dengan demikian menunjukkan bahwa penggerak peristiwa dalam adegan ini diperankan oleh Jambumangli, sampai para raja pelamar melarikan diri meninggalkan negara Ngalengkadiraja. Rangkaian peristiwa dalam jejer I ini bergerak secara linier.

Sampai berakhirnya jejer I masih menunjukkan kesinambungan yang logis. Jejer II merupakan pencabangan jalan cerita, yaitu menghentikan cerita di Ngalengkadiraja untuk ganti cerita di negara Lokapala. Fenomena demikian lazim berlaku dalam tradisi wayang yang menggunakan alur spiral yang sering kali ditandai oleh salah satu kalimat narasi "séjé prenahé, bareng angkaté ning tunggal kandhané awit èwet kalamun ta sinarengna" (lain wilayah, [terjadi] dalam waktu yang sama oleh karena dalam satu cerita tidak mungkin diceritakan bersamaan). Model demikian merupakan salah satu ciri khas pola alur wayang, yaitu tidak linier (bandingkan dengan Wahyudi, 2012: 206). Peristiwa selanjutnya bergerak secara linier yang memaparkan perjalanan Wisrawa menuju negara Ngalengkadiraja. Jalan cerita berhenti sampai di sini, kemudian jalan cerita berpindah pada peristiwa yang lain.

Peristiwa selanjutnya terjadi di Karang Kabolotan. Di sini tempat kejadian sudah berubah, tetapi peristiwa ini merupakan kelanjutan dari peristiwa sebelumnya, yaitu jejer II. Sebelum Wisrawa menuju Ngalengkadiraja, terlebih dahulu menuju Karang Kabolotan untuk mengajak Semar beserta anak-anaknya menyertainya menuju ke Ngalengkadiraja. Namun demikian peran panakawan ini tidak tampak dalam rangkaian peristiwa yang terjadi di Ngalengkadiraja, kecuali Pétruk dan Bagong setelah Sukèsi menerima ajaran ngèlmu sastrajén$d r a$, dan itu pun dirasa mengganggu serta kurang logis. Dikatakan demikian karena di sana tidak ada tanda mengenai perpindahan setting, artinya adegan tersebut tentu masih berada di sanggar palanggatan. Padahal tempat tersebut merupakan tempat larangan untuk didekati oleh siapa pun sesuai dengan persyaratan dalam mengajarkan ngèlmu sastrajéndra, yaitu "kutu walang ataga tan kena hamiyarsa". Jangankan manusia, binatang dan bahkan tumbuhan pun tidak boleh ikut mendengarkan. Oleh karena itu dengan kehadiran Pétruk dan Bagong di sana justru peristiwa menjadi kon- 
tradiktif, atau tidak terbangun satu kesatuan logika yang utuh. Sangat mungkin bahwa kehadiran Pétruk dan Bagong tersebut sebagai upaya untuk menampilkan lawakan-lawakan dalam mencairkan suasana, namun hanya tempatnya yang kurang tepat, karena justru membangun kontradiksi dalam satu kesatuan lakon.

Peristiwa bergerak pada perjalanan Wisrawa, yakni di tengah hutan bertemu dengan Ditya Kala Klanthang Mimis yang menghadangnya. Peristiwa bergerak menjadi perselisihan dan berakhir dengan perang yang dimenangkan Wisrawa. Peristiwa berhenti di sini, jalan cerita pindah ke negara Ngalengka.

Adegan Ngalengka diawali dengan dialog Prabu Sumaliraja dengan Prahastha, putranya; kemudian datang Begawan Wisrawa. Persoalan yang dibicarakan di sini pada dasarkan kurang kuat dijadikan alasan untuk sebuah adegan karena hanya perintah Prabu Sumaliraja kepada Prahastha untuk berhati-hati yang kemudian disusul kehadiran Wisrawa. Artinya dapat diasumsikan bahwa adegan tersebut hanya disediakan untuk mewadahi kedatangan Wisrawa. Seandainya demikian akan menjadi relatif efektif apabila dalam adegan tersebut Wisrawa sudah berada di sana, sehingga adegan tersebut memang muncul karena kedatangan Wisrawa. Dalam peristiwa ini, keberadaan panakawan tidak terceritakan, demikian juga Jambumangli.

Peristiwa selanjutnya bergerak secara linier yaitu Begawan Wisrawa meruwat Prabu Sumaliraja yang kemudian dilanjutkan meruwat Dewi Sukèsi. Di sini terjadi pengembangan jalan cerita yaitu akibat dari tindakan Begawan Wisrawa yang mengajarkan Sastrajéndra Hayuningrat Pangruwating Diyu menimbulkan gara-gara di Kahyangan Bathara Guru sehingga membuat Bathara Guru bersama Bathari Uma turun ke marcapada menuju tempat Begawan Wisrawa bersama Dewi Sukèsi, yang kemudian kedua dewa-dewi merasuki kedua insan. Akibat dari pengaruh Bathari Uma di dalam tubuhnya, Dewi Sukèsi menjadi jatuh cinta kepada Begawan Wisrawa; demikian juga dengan Begawan Wisrawa pun mengimbangi keinginan Dewi Sukèsi akibat pengaruh Bathara Guru dalam tubuhnya, yang selanjutnya keduanya memadu cinta.

Peristiwa selanjutnya bergerak ke istana kerajaan Ngalengkadiraja, yakni Prabu Sumaliraja mengetahui peristiwa yang terjadi atas Begawan Wisrawa dengan Dewi Sukèsi, dan keduanya kemudian dinikahkan. Pergerakan peristiwa ini hanya dipaparkan melalui kandha, yang dalam tradisi pedalangan disebut dengan istilah pagedhongan atau digedhong.

Peristiwa selanjutnya bergerak ke adegan di Kasatriyan Argalobang, tempat Jambumangli. Jambumangli menanyakan kepada prajurit sandi mengenai peristiwa yang terjadi di istana. Dikatakan oleh prajineman bahwa Sukèsi telah diperistri oleh Begawan Wisrawa. Pergerakan peristiwa ini tampak masih mengikuti teks Ki Nartosabdo secara utuh tanpa dikritisi. Apabila dicermati peristiwanya, keadaan tersebut menunjukkan adanya jalinan peristiwa yang kurang utuh. Pertama; apabila posisi Kasatriyan Argalobang jauh dari istana, tentu Jambumangli tidak akan berlama-lama tinggal di kasatriyan karena persoalan Dewi Sukèsi belum selesai. Dia akan selalu mengawasi istana, baik dilakukan sendiri maupun oleh pasukan sandinya. Dengan demikian kedatangan Begawan Wisrawa beserta panakawan akan tidak luput dari pengawasannya. Oleh karena itu keterlambatan Jambumangli mengenai kabar pernikahan Dewi Sukèsi dengan Begawan Wisrawa menjadi kurang menyatu dengan peristiwa di awal lakon. Hal demikian tentu akan berbeda ketika Jambumangli mengetahui kedatangan Begawan Wisrawa lalu sayembara perang, Jambumangli terbunuh, barulah proses peruwatan dilakukan. Dengan demikian jelas bahwa penempatan urutan sangat berpengaruh pada keutuhan logika lakon berdasarkan tema, alur, dan kapasitas tokohnya.

Persoalan juga dijumpai ketika peristiwa bergerak ke jalan cerita Prabu Danapati di Lokapala. Dialog Prabu Danapati: "Yèn ora sisip panduluku iki kaya pisowané Tumenggung Tenung Gohmuka, ana apa tanpa katimbalan maju ana pangarepanku" ('Kalau tidak salah, yang datang ini adalah Tumenggung Gohmuka. Ada apa tanpa saya panggil kamu menghadap?'). Dari dialog ini ada indikasi bahwa Prabu Danapati tidak memahami kapasitas dan peran Gohmuka dalam lakon. Dengan demikian kehadiran tokoh Gohmuka di sini merupakan peristiwa yang benarbenar baru, baik bagi pembaca maupun Danapati sendiri karena tokoh tersebut tidak disebutkan di peristiwa sebelumnya. Dengan demikian peristiwa 
tersebut tidak memiliki relasi sintagmatik dengan peristiwa yang lainnya. Sementara apabila melihat dialog Gohmuka di sini menunjukkan bahwa Gohmuka memiliki peranan yang sangat penting sebagai pembangun suasana hati Prabu Danaraja dan sekaligus penggerak peristiwa. Terlebih lagi bila mencermati dialog Gohmuka "sebagai duta penglawung" ('utusan duka') menunjukkan bahwa Gohmuka adalah seorang duta. Tetapi di sini tidak jelas kedudukan Gohmuka, apakah dia sebagai duta Wisrawa atau Danapati. Hal demikianlah yang menyebabkan tidak terbangunnya jalinan peristiwa yang utuh dan logis. Terlebih lagi ketika pergerakan peristiwa di sini dilakukan secara tiba-tiba, tanpa penandaan, baik melalui dialog maupun narasi, keterputusan alur cerita tersebut semakin terasa. Berbeda dengan peristiwa yang ditampilkan dalam Lakon Alap-alapan Sukèsi, dalam jejer I telah ditampilkan bahwa Gohmuka memang ditugaskan untuk menyertai Begawan Wisrawa pergi ke Ngalengkadiraja, dan tokoh ini pun dimunculkan dalam beberapa peristiwa dan adegan. Dengan demikian kedatangan Gohmuka di Lokapala menjadi logis.

Peristiwa selanjutnya adalah adegan di Ngalengkadiraja, yaitu Danapati berhadapan dengan Begawan Wisrawa. Peristiwa ini ditampilkan sangat singkat hanya melalui lima dialog. Apabila mencermati dialog Danapati dalam adegan ini:

Danapati : "Kula kedah kados pundi Rama, putri ingkang kaboyong kedahipun dadi bojoné anaké, lha kokjebul malah dinggo dhéwé. Hemmmm.... Kula lajeng kedah mawi étangan ingkang pundi Rama, nék kula nggegegi dadi ratu, Rama menika kénging pradata merga lirwa kuwajiban, nanging menawi hangèngeti Rama menika tiyang sepuh ingkang ngukir jiwa raga kula, napa badhé kula mentala, bapa karo anak bandayuda merga rebutan wong wadon. Badhé dosa menapa ingkang kula sandhang yèn kula wani karo bapak kula dhéwé, merga prekara kasusilan. Iki lelakon apa. (Emosi) Mugi jagad neksèni ucap kula niki Rama, mbénjing menawi putranipun Rama ingkang patutan kaliyan Dèwi Sukèsi mijil kakung badhé dados mungsuh bebuyutan, sampun
Rama kula nyuwun pamit saha nyuwun pengèstu wangsul dhateng Lokapala." menunjukkan bahwa Danapati tidak dapat berbuat banyak ketika berhadapan dengan ayahnya. Ada dua pemahaman yang dapat ditafsirkan dari dialog di atas, yaitu (1) Danapati tidak berani melawan ayahnya, baik itu takut dosa atau pun takut terhadap kesaktian ayahnya; (2) Danapati adalah raja yang tidak tegas dan tidak adil. Danapati tidak menghukum Wisrawa yang telah berkhianat kepada raja karena Wisrawa adalah ayahnya. Artinya Danapati adalah raja yang mban cindhémban siladan (membeda-bedakan dalam penerapan hukum). Apalagi bila direlasikan dengan dialog Danapati dalam adegan sebelumnya:

Danapati: "Dudu karepé dhéwé, Banindra lan Gohmuka ketapna wadyabala ayo dilurugi negara Ngalengkadiraja dadèkké samodra geni."

dialog tersebut menunjukkan bahwa Danapati memerintahkan semua prajurit untuk membasmi negara Ngalengkadiraja. Namun kenyataannya, setelah berhadapan dengan Begawan Wisrawa semuanya berbalik. Hal ini juga dapat dipandang melemahkan kapasitas kerajawian Danapati, yakni raja yang tidak bawa laksana, tidak dapat dipercaya perkataannya. Kesan yang ditangkap dari peristiwa tersebut adalah Danapati adalah seorang raja yang lebih baik malu dari pada mati. Hal demikian bertentangan dengan kriteria raja yang utama dalam pandangan Jawa. Artinya bahwa Danapati bukanlah golongan raja utama, bahkan sebaliknya sebagai raja yang memalukan. Fenomena demikian akan menjadi tidak nyambung dengan peristiwa lain dalam intertekstualitasnya, yakni kelak Danapati diangkat menjadi dewa. Yang menjadi pertanyaan adalah apa yang menjadi dasar untuk mengangkat Danapati menjadi dewa, sedangkan dia bukanlah golongan raja utama. Padahal apabila dicermati secara keseluruhan cerita Lokapala, perisitiwa inilah yang menjadi landasan untuk mengangkat Danapati menjadi dewa; dan sayangnya persoalan demikian tidak diberi penekanan dalam Lakon Sastrajéndra Hayuningrat Pangruwating Diyu ini.

\section{Penutup}

Berdasarkan uraian di atas dapat disimpulkan bahwa lakon konvensional yang sebenarnya 
dilaksanakan selama kurang lebih delapan jam bisa diringkas menjadi sekitar tiga sampai empat jam. Langkah demikian bisa dilakukan dengan mengurangi beberapa adegan serta meringkas dialog dibuat sedemikian ringkas, bahkan kadangkadang dalam satu adegan hanya menampilkan dua dialog saja. Tentunya langkah demikian bukan berarti tanpa konsekuensi, baik kekurangan maupun kelebihannya. Kelebihannya adalah waktu menjadi lebih singkat sehingga penonton tidak perlu berlama-lama duduk hingga semalam suntuk. Dengan waktu yang relatif singkat, penonton bisa menikmati cerita sampai selesai, sehingga bagi yang esoknya harus bekerja tidak mengantuk. Namun demikian kelemahannya adalah pertunjukan menjadi terkesan terburu-buru sehingga penonton kurang bisa menikmati jalannya pertunjukan. Terlebih lagi, apabila dalang kurang mampu membawakannya, pertunjukan justru akan terkesan melelahkan. Hal yang paling pokok tereduksi adalah dalam format yang demikian pertunjukan akan berfokus pada pemaparan cerita sehingga makna, misi, ataupun aspek yang lain seakan-akan kurang memiliki ruang, bahkan persoalan pokok dalam intertekstualitasnya menjadi terabaikan. Di samping itu, dalang akan terpancang pada naskah dan ruang improvisasi menjadi semakin sempit.

Oleh karena itu persoalan yang menjadi perhatian serius dalan garap-ulang atau pun karya lakon baru dalam dunia pedalangan adalah pemilihan tema, pemilihan tokoh dan kapasitasnya, alurnya, serta settingnya. Yang kesemuanya itu harus diperhatikan intertekstualitasnya. Semoga tulisan singkat ini memberikan inspirasi untuk semakin menggiatkan karya-karya baru dalam dunia pedalangan. Semua yang sudah dilakukan oleh Njajah Désa Milang Kori di atas, terlepas dari kekurangan dan kelebihannya, merupakan langkah yang sangat positif dan perlu dilakukan kajian yang terus-menerus agar diperoleh format yang relatif mampu mengatasi kelemahan-kelemahan tersebut sehingga berbagai kebutuhan dapat terakomodasi.

\section{Kepustakaan}

a. Acuan

Bandem, I Made. 2000. “Seni Tradisi di Tengah Arus Perubahan”, dalam IDEA, Jurnal Ilmiah Seni Pertunjukan. Yogyakarta: PT Tarawang Press.

Becker, Alton L. 1979. "Text-Building, Epistemology, and Aesthetics in Javanese Shadow Theatre" in Alton L. Becker and Aram Yengoyan, Editor. The Imagination and Reality: Essays on Southeast Asian Coherence Systems, Norwood, New Jersey: Ablex Publishing Corporatuon.

Kasidi. 2000. "Pengembangan Struktur Pergelaran Wayang Gaya Yogyakarta Masa Kini”, dalam IDEA Jurnal Ilmiah Seni Pertunjukan. Yogyakarta: PT Tarawang Press. , 2009. Suluk Wayang Kulit Purwa Gaya Yogyakarta. Yogyakarta: Penerbit Bagaskara

Mujanattistomo dkk. 1977. Pedhalangan Ngayogyakarta Jilid I. Yogyakarta: Yayasan Habirandha.

Nojowirongko. 1960. Serat Tuntunan Pedhalangan Tjaking Pakeliran Lampahan Irawan Rabi Djilid I. Jogjakarta: Tjabang Bagian Bahasa.

Padmosoekotjo, S. 1958. Ngengrengan Kasusatran Djawa I. Jogjakarta: Penerbit \& Toko Buku Hien Hoo Sing.

Spillane, James J. 1987. Ekonomi Pariwisata, Sejarah dan Prospeknya. Yogyakarta: Penerbit Kanisius.

Wahyudi, Aris. 2012. Lakon Dewa Ruci: Cara Menjadi Jawa. Yogyakarta: Penerbit Bagaskara. , 2014. "Sambung-rapet dan Gregetsahut dalam Dramaturgi Wayang" dalam Wayang Nusantara: Journal of Puppetry. Vol. 1 No. 1, September 2014.

\section{b. Audio-Visual}

Ki Nartosabdo, 2009. Dasamuka Lahir. (kaset) PT Bintang Fajar Cassete. 